\title{
A framework for characterising infrastructure interdependencies
}

\section{Neil Carhart* and Ges Rosenberg}

\author{
Department of Civil Engineering, \\ University of Bristol, \\ Queens Building, University Walk, \\ Bristol, BS8 1TR, UK \\ Email: neil.carhart@bristol.ac.uk \\ Email: ges.rosenberg@bristol.ac.uk \\ *Corresponding author
}

\begin{abstract}
The interdependencies within and between infrastructure systems can produce benefits and risks. The perception and value of these relationships can vary significantly depending on the viewpoint of the actors within the system. The current methods for describing these relationships do not necessarily account for these different perspectives, and tend to focus on reducing the risks and vulnerabilities associated with interdependency. By taking a holistic, multi-stakeholder approach of the infrastructure system it is possible to also identify the proactive opportunities for improving efficiency, effectiveness and resilience that can emerge from the relationships. A taxonomy is presented which allows for the characterisation of infrastructure relationships in multiple dimensions, with particular focus on identifying opportunities in a way that is therefore complementary to current methods. An application of this taxonomy to the identification of potentially beneficial relationships within the UK infrastructure system is described.
\end{abstract}

Keywords: infrastructure interdependency; system-of-systems; systems architecture framework.

Reference to this paper should be made as follows: Carhart, N. and Rosenberg, G. (2016) 'A framework for characterising infrastructure interdependencies', Int. J. Complexity in Applied Science and Technology, Vol. 1, No. 1, pp.35-60.

Biographical notes: Neil Carhart is a Research Associate within the International Centre for Infrastructure Futures (ICIF) as well as the University of Bristol's Systems Centre. His research has included the development and implementation of new accident modelling techniques and process to enhance socio-technical resilience within high-hazard industries. Under ICIF he is involved in researching the planning and management of emergent properties within the infrastructure system-of-systems in order to enhance the value proposition and ensure the sustainable delivery of the valued society outcomes it facilitates. This has looked at supporting resilience at all levels of the system from the individual user to the governance structures and the critical role that learning and education play in managing the complex challenges of the future. He is also the editor of the Hazards Forum Newsletter.

Ges Rosenberg is a Research Fellow in the Engineering Systems and Design Research Group at the University of Bristol focussed on systems-based, interdisciplinary approaches to engineering. His key themes include uncertainty management, evidence-based decision making, sustainability, resilience and 
creating value through co-design of innovative business models. His research includes co-developing the interdependency planning and management framework for UK Treasury's Green Book supplementary guidance: valuing infrastructure spend. He is the Network Manager for the EPSRC-funded project 'Redistributed Manufacturing | Resilient Sustainable City'. His prior background is in aerospace engineering including mathematical modelling, simulation and analysis of linear and nonlinear dynamic systems, and controls-structures interaction.

This paper is a revised and expanded version of a paper entitled 'Establishing a common language of infrastructure interdependency' presented at the International Symposium for Next Generation Infrastructure, Vienna, Austria, 30 September to 1 October 2014.

\section{Introduction}

Infrastructure systems can exist interdependently with one another either by design, by necessity or through evolution. There is widespread evidence that interdependence can be the source of emergent benefits and hazards, and therefore there is value in its identification and management (Frontier Economics, 2012). Achieving this requires collaboration and communication between infrastructure stakeholders across all relevant sectors. Collaboration can develop 'situational awareness' (Endsley, 1995), that is to say a holistic knowledge of the infrastructure landscape and therefore potential interdependencies.

As a result of the perceived vulnerabilities and opportunities which emerge from infrastructure interdependency, there is an increased interest in modelling and understanding them from those in a position of governance (HM Treasury and Infrastructure UK, 2011).

There are many methods for modelling the interdependency between infrastructure elements, each serving a specific purpose and providing a different conception of what interdependency means in relation to infrastructure. Some differing conceptions of infrastructure interdependency can be attributed to the multiple viewpoints of the stakeholders responsible for commissioning, financing, planning, designing, building, operating and using infrastructure. For example, there was a significant increase in research into infrastructure interdependencies following the Oklahoma City bombing in 1995 (Heller, 2002), primarily as a result of Presidential Decision Directive 63 (The Clinton Administration, 1998) which stressed the importance of infrastructure interdependency in terms of national vulnerability. This influenced a focus on the vulnerability emergent from interdependency. The resultant modelling tools focussed on understanding those risks, often as discrete from understanding the potential benefits of interdependency.

Without a reflection on the meaning of infrastructure interdependency, and without the means to describe it completely and consistently, there is a danger that one particular understanding of infrastructure interdependency, for example in terms of producing vulnerability; one particular modelling approach, for example network theory; or one particular type of interdependency, for example the physical transfer of resources; become dominant at the expense of others. 
Infrastructure in this context is viewed not just as discrete assets and services within particular industrial sectors, but also as a holistic system-of-systems arising from the interdependencies and relationships between the constituent elements. The Royal Academy of Engineering (2007) describes a system as "a set of parts which, when combined, have qualities that are not present in any of the parts themselves. Those qualities are the emergent properties of the system". It is these emergent properties, the outcomes of the systems and interdependencies, that may be engineered to benefit society and provide the purpose for the infrastructure systems. The Royal Academy goes on to say: "Engineers are increasingly concerned with complex systems, in which the parts interact with each other and with the outside world in many ways - the relationships between the parts determine how the system behaves". Thus, understanding the connections between the components within the purposeful dynamic structures which underlie society is central to understanding how to deliver the behaviours society requires.

Systems theory suggests that the complete, holistic view of a system can rarely be effectively captured by one single model or modelling approach. This is particularly true of the complex socio-technical systems from which infrastructure is comprised. Instead it is necessary to have a meta-model or a framework which brings together all models which represent different aspects and views of the system into one coherent and internally consistent architecture (Kruchten, 1995; Zachman, 1987) as used in the architectural frameworks existent in domains from defence (Department of Defense, 2009) to railways (TRAK Steering Group and Department for Transport, 2013). These frameworks show how multiple viewpoints can be represented concurrently and coherently by different modelling approaches, each catering to the needs and nuances of a particular viewpoint. These system architectures, in which multiple perspectives are developed for the same underlying system, have the advantage of providing an efficient and effective means of communicating with multiple stakeholders.

In a similar way, the language of infrastructure interdependency needs to recognise the likelihood that different stakeholders will have differing perspectives on a network of infrastructure and on the associated interdependencies. It has been widely recognised in the modelling of infrastructure interdependencies that there no single model or modelling approach is enough to capture all sides of this problem (Johansson and Hassel, 2010). It therefore follows that multiple modelling methodologies would also benefit from such a framework. This would ensure that the system of interest was not only modelled from multiple perspectives, but that the emergent properties of beneficial and adverse interactions between infrastructure systems was also understood.

The first step in achieving this is to consider all the different types of infrastructure interdependencies, and the language used to describe them. This is fundamental to providing a means of relating the shared understanding of infrastructure interdependencies to the interests of the different stakeholders. For example, an engineering perspective may tend to focus on physical interactions and information flows between infrastructure systems and use these to identify issues of network resilience. While, no doubt concerned by issues of physical resilience, an investor in infrastructure is also likely to take an interest in economic resilience, the flow of financial capital, economic interdependencies and in any opportunities to generate additional value through the exploitation of infrastructure interdependency. 
Without a consideration of this language there is a danger that certain forms of interdependency will dominate, and opportunities which arise from other forms will be missed.

Recognising, developing and sharing multiple understandings of infrastructure interdependency will facilitate a wide range of future multi-disciplinary and cross-sectorial work and support productive cross-sector stakeholder dialogues. It will also help with the systematic search for interdependencies and the construction of a more holistic view of the infrastructure system.

This paper aims to extend a discussion around the nature of infrastructure interdependency and dependency in order to establish the basis of a useful, coherent and complete conceptual taxonomy. The next two sections provide a brief introduction to the characterisation of infrastructure interdependency, and the role modelling interdependencies has had on how these relationships are conceived and described.

From these two areas a common language for describing interdependency is extracted and proposed from theory, practice and their intersection. New dimensions of interdependency and its context are suggested to extend and complement those synthesised from studies elsewhere. The final section applies the taxonomy to a case study seeking to identify potentially beneficial relationships and interdependencies within the UK infrastructure system. It reports on the frequency of each of the interdependency characteristics.

\section{Characterising interdependency}

The Oxford English Dictionary (OED Online, 2015) identifies the earliest usage of 'interdependency' as 1822, defining the term as "The fact or condition of depending each upon the other; mutual dependence". This literal interpretation of mutual dependence is however not always borne out in its practical usage as will be seen below. The focus here is on the modern usage specifically within the context of infrastructure.

Figure 1 Google Ngram for 'infrastructure interdependency' and 'interdependent infrastructure' (see online version for colours)

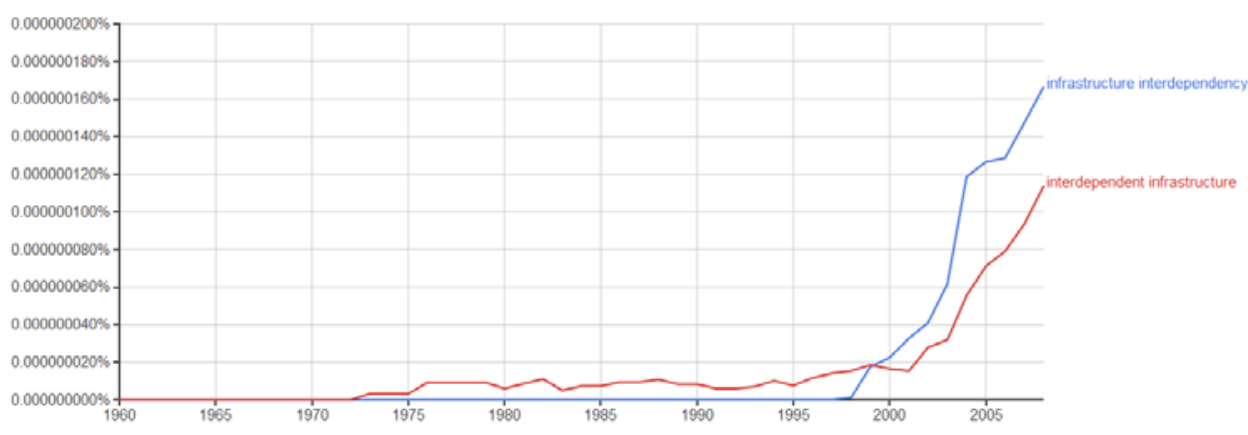


Figure 1 provides an indication of the usage of 'infrastructure interdependency' and the variant 'interdependent infrastructure' by way of an Ngram (Google Books Ngram, 2015) as described by Michel et al. (2011). This search was performed on the 'English 2012' dataset of books published predominantly in the English language in any country between 1800 and 2008 (with a smoothing factor of 3). Not only does this highlight the increase in usage in the first decade of the 21st Century, but it also highlights the influence of the previously described Presidential Decision Directive in 1998 and the subsequent work looking at infrastructure interdependency in terms of fragility.

As interest grew, so did the work concerning the nature of infrastructure interdependency. One of the most influential papers exploring this came from Rinaldi et al. (2001). This has been identified as the only completely self-contained classification system (Ouyang, 2014) although others have argued for the need for a richer framework (Zimmerman and Restrepo, 2006; Zimmerman, 2008). It outlines six dimensions to frame interdependency, which will be reported here as seven by splitting 'coupling and response behaviour' into two separate dimensions. The first two relate to the characterisation of the interdependency relationship itself and will form the starting point for the taxonomy described in this paper. These are the type of interdependency and the degree of coupling:

1 type of interdependency:

- $\quad$ physical (a physical output from one system is a necessary input to another)

- $\quad c y b e r$ (information produced by a system affects the operation of another)

- geographic (two or more systems are considered to be co-located in space)

- logical (a mechanism that could be organisational or social).

2 coupling

- $\quad$ tight (a close correlation in time or scale)

- $\quad$ loose (a distant correlation in time or scale).

The remaining five dimensions extend this framework to also describe the context and results of the interdependency: infrastructure environment; response behaviour; infrastructure characteristics; types of failure, and; state of operations. The inclusion of 'type of failure' reflects the historic consideration of interdependencies as a source of unwanted risk, but not opportunity. These contextual factors, while important, will be initially put aside in order to focus on the description of the relationships themselves.

\section{Modelling interdependency}

Alongside those who have specifically set out to describe the different dimensions of infrastructure interdependency are those who attempt to model it. In doing so they either utilise existing frameworks, or through the process of modelling, identify alternative ways of characterising and describing interdependency. Differences stem from the purpose and methods used to conduct the modelling.

Previous reviews (Bloomfield et al., 2009; Ouyang, 2014; Pederson et al., 2006) have identified numerous qualitative and semi-qualitative attempts to model interdependency including: network and graph theory; topological models; petri-nets; input-output models; agent-based models; spatial and time-series analysis; matrix representations and 
hierarchical risk models. These are frequently complementary to one another, each revealing different aspects of the emergent properties of interconnected infrastructure systems, which would benefit from a framework which brings them together.

A study by Satumitra and Duenas-Osorio (2010) of 162 published papers on infrastructure interdependency modelling identified over 40 different modelling tools and approaches. By far the two most popular approaches were based on network and graph theory and input-output models (around 22\% each) followed by agent-based models $(11 \%)$. Each of these modelling approaches has different strengths and weaknesses when it comes to modelling the dimensions and characteristics of interdependency. For example, it has been suggested (Ouyang, 2014) that input-output models are only effective at capturing physical and digital interdependencies, and it has been found that very few approaches capture both functional and geographic interdependencies (Johansson and Hassel, 2010). This is not a shortfall in input-output modelling, but failing to realise it, and believing a single model can give the whole interdependency picture is a potential source of error.

If the different types of interdependency are not explicitly considered in the early stages of a project, and each modelling approach specialises in a particular type of interdependency, then the choice of model can unintentionally narrow the view of what constitutes interdependency.

Figure 2 Discrete approaches to modelling the infrastructure system of systems, (a) complex 'reality' (b) discrete sector/component approach (c) discrete interdependency type approach (see online version for colours)

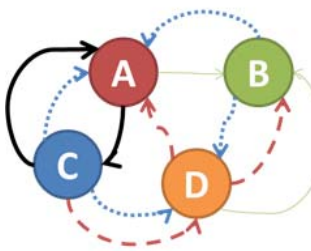

(a)

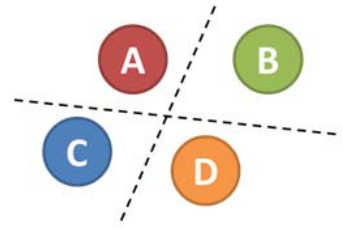

(b)

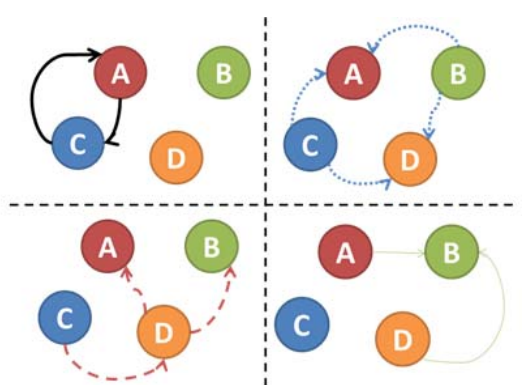

(c)

Without a robust framework that recognises the different dimensions of interdependency and brings the models together in a coherent way, there is a danger that in trying to address an approach that places boundaries around infrastructure sectors, boundaries are instead placed around interdependency types, and a partial picture remains. This is represented in Figure 2 where (a) represents a network comprised of four elements (A, B, $\mathrm{C}$ and $\mathrm{D})$ from different infrastructure sectors. They are connected by means of four very different relationships. For example $\mathrm{A}$ and $\mathrm{C}$ may be dependent upon each other for the provision of physical resources such as fuel or water, while D and B may be connected by both a flow of information and by virtue of their close proximity. Traditionally, as in (b), these relationships may have been ignored leading to multiple disconnected partialviews based on specific sectors; while (c) also represents the creation of multiple partialviews, this time the division is made according to the particular type of interdependency that connects all the elements, a decision implicitly made by the choice of modelling 
approach. Due to the complex multi-sectoral and multidisciplinary nature of infrastructure development (not to mention the philosophical limitations of modelling) any attempt at capturing the whole system of systems will be partial in some way. The challenge lies in integrating the different evidence, data and models in a comprehensive and coherent way with respect to both different sectors and different forms of interdependnecy.

This situation is further complicated when considering the different types of elements that combine to create an infrastructure system. Figure 3 illustrates this with a simplified conceptual model of an infrastructure system. In this simplification the infrastructure system has three types of components: governance artefacts (e.g. regulations), operational functions (e.g. water treatment) and physical assets (e.g. hydraulic pumps). In reality this division is likely to be far more complicated. The interdependencies between elements within any one of these layers may be very different from those within any other. Similarly the interdependencies which connect elements across the layers may be characteristically different again.

Figure 3 Simplified layered model of a socio-technical infrastructure system (see online version for colours)

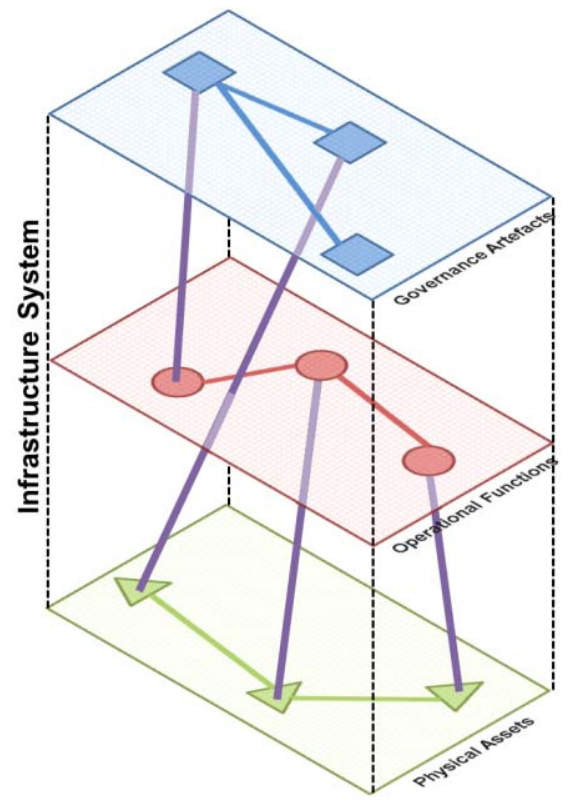

The specific terminologies that make sense to describe interdependencies within one layer may not make sense to describe the interdependencies between layers. Additionally many different interdependencies may exist between infrastructure systems (as shown in Figure 3 and Figure 4), and at different points in the life-cycle of these systems. To ensure a complete picture is obtained, a robust means to describe these different interdependency types is required. This should not be seen as a rejection of any single modelling approach, or an underappreciation for their strengths; it is instead a recognition and endorsement of their complementary nature, and the emergent transformations possible from bringing together the multiple-perspectives they offer. 
Figure 4 Interdependencies between simplified layered socio-technical infrastructure systems (see online version for colours)

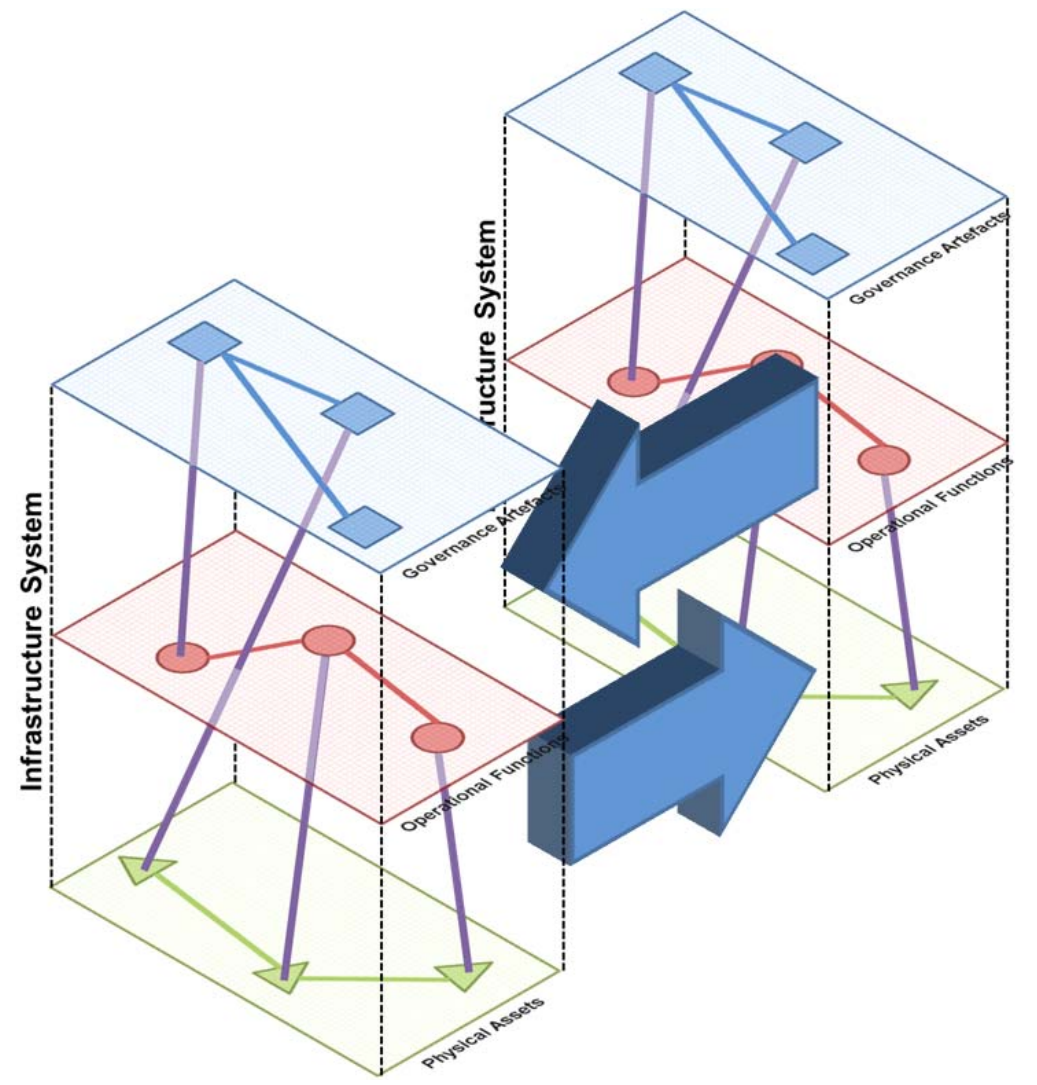

\section{Interdependency description framework}

This section brings together and develops the work of those focused on characterising infrastructure interdependency, as well as the experiences of those modelling it. It also introduces a number of additional characteristics identified from case studies specifically seeking to identify opportunities from infrastructure interdependency (Rosenberg and Carhart, 2013). This synthesis results in a more complete framework with which to identify and describe infrastructure interdependency. This is purposefully constructed as a qualitative framework to help characterise infrastructure interdependencies and guide the integration of different approaches.

\subsection{Directionality}

So far the term 'interdependency' has been used exclusively; however it is necessary to consider the similarities and differences between dependency and interdependency. Despite a distinction in their formal definition they are in many instances used seemingly interchangeably. 
Infrastructure interdependency has specifically been described as both a distinctly bidirectional relationship (Laprie et al., 2007; Rinaldi et al., 2001) and elsewhere in such a way that includes both bidirectional and non-reciprocal dependency in the form of an influence from one element on another (HM Treasury and Infrastructure UK, 2011; Pederson et al., 2006). Others have made this distinction by referring to 'input' only and 'mutual' interdependencies (Eusgeld et al., 2011).

In an attempt to model infrastructure interdependency formally Dudenhoeffer et al. (2006) define it as: "a relationship between infrastructures and represented as the edge $(a, b)$ which implies that node b is dependent on node a". They add that "Depending on the nature or type of the relationship, this relationship may be reflexive in that $(a, b) \rightarrow$ $(b, a)$ " implying it is not necessarily so, but can still be described as an interdependency.

The UK Cabinet Office have used the term to mean "mutual reliance among infrastructure owners and operators on services from other suppliers" [HM Government Cabinet Office, (2011), p.11] which implies an interdependency between two elements can emerge from two non-reciprocal dependencies on a third-party. The UK National Infrastructure Plan of the same year (HM Treasury and Infrastructure UK, 2011) describes interdependency with a non-reciprocal dimension as "where the impact of change in one network are felt in other networks".

It could be questioned whether a non-reciprocal dependency is actually possible in terms of infrastructure, as a physical dependency on energy or resources for example would likely be balanced by a financial compensation which may arguably set up a separate but related economic dependency. Thus the notion of a non-reciprocal dependency being part of an interdependent relationship may make most sense when considering the different types of interdependency in isolation. This aligns with the suggestion that bidirectional relationships exist at the macro system or system-of-systems level, whereas non-reciprocal dependencies are more common at the component level (Johansson and Hassel, 2010).

\subsection{Order}

Discussions of the fundamental definition of infrastructure interdependency and its modelling have also led to the distinction between first, second and third order dependencies (Johansson and Hassel, 2010; McDaniels et al., 2007; Rinaldi et al., 2001).

Figure 5 depicts three infrastructure systems: A, B and C. The arrows in this figure represent the provision of a service, resource or function from one infrastructure to fulfil a dependency. In other words, system A provides a service to system B, and system B is dependent on this service, and therefore dependent on system A.

Figure 5 Dependency chain (see online version for colours)

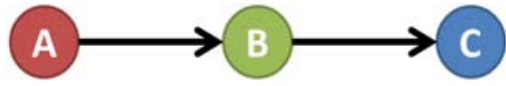

A first order dependency is where system B is directly dependent on system A, and a second order dependency is where system $\mathrm{C}$ is indirectly dependent on system A via system C's first order dependency on system B. These indirect effects can lead to feedback loops where the second order dependency means A affects B which then affects A (Little, 2002). This implies that where they form feedback loops, second order 
dependencies could also be described as interdependencies. Third order dependencies introduce a further intermediary system.

The order of the interdependency can be further complicated by considering more complex network topologies such as the one suggested by the Cabinet Office definition [HM Government Cabinet Office, (2011), p.11] and depicted in Figure 6. Here system A provides a service, resource or function to both system B and system $C$ such that it could be said systems $B$ and $C$ share a dependence on system $A$. The precise nature of each of these relationships however may mean that systems B and C, despite having no direct interaction and requiring nothing from each other can have an influence on each other. This is particularly the case if the nature of system A's provision is finite such that the demand of $\mathrm{B}$ can influences the availability to $\mathrm{C}$.

Figure 6 Alternative network topology (see online version for colours)

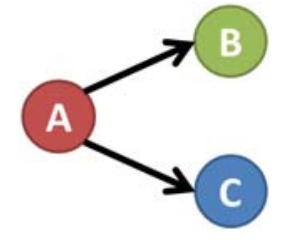

While both $\mathrm{B}$ and $\mathrm{C}$ could be described as having a first order dependency on $\mathrm{A}$, the nature of the relationship between $\mathrm{B}$ and $\mathrm{C}$ is harder to characterise. A further study of network motifs could identify the many different topologies into which an arrangement of dependencies and interdependencies can form. The language for describing infrastructure interdependency is not as well formed for addressing such topologies.

\subsection{Coupling}

Rinaldi et al. (2001) also propose a dimension relating to the strength of the relationship between the two elements or systems. They refer to this as the degree of coupling from tight to loose as in Perrow's (1984) classification of systems, and affect the way in which effects propagate (Little, 2002). Tight coupling refers to a situation where changes in one system impact with another in close correlation, usually in time. If systems are loosely coupled then while there is a causal connection, there is a delay between the cause and the effect. Such time lags can present significant challenges in problem structuring and their effects should not be over-looked. Others have looked to assess this degree of influence associated with an interdependency on a quantitative scale (Huang et al., 2014). There is scope for additional work on how the degree of coupling can be quantified across the spectrum of interdependency types as described by the other characteristics.

\subsection{Location}

The UK Cabinet Office (2011) distinguishes between two types of interdependency relationship which are subjective to the viewpoint from the elements or components at either end of the relationship. The first of the two types are upstream dependencies. These are dependencies which provide a service, function or resource to the element of interest. In Figure 5, system A provides a service to system B, from system B's perspective this relationship can be described as an upstream dependency. System B 
provides a service to system C, so from system B's perspective this relationship can characterised as a downstream dependency. From system A's perspective, its relationship with system B could be described as a downstream dependency. Hence the same relationship can be described in two different ways as contingent on the specific viewpoint. Additionally, there are certain types of dependency (such as geographic interdependencies) for which the idea of upstream and downstream characteristics have no meaning.

\subsection{Type}

There have been several attempts to characterise interdependency into descriptive types in addition to those proposed by Rinaldi et al. (2001). Those four types actually reflect four earlier interdependency typologies for product design matrices proposed by Pimmler and Eppinger (1994): materials, energy, information and spatial. What is clear from both of these is that interdependencies can be more than an output from one system becoming a necessary input to another.

Pederson et al. (2006) use an expanded version of an earlier taxonomy (Dudenhoeffer et al., 2006) which splits logical interdependencies into two further groups: policy/procedural and societal. Indeed many complex, logical dependencies and interdependencies are created through human actions and perceptions, as Brown (2008) writes:

"The state of, or perceived risks in, one infrastructure could influence behaviors/operations in another infrastructure due to loss of confidence in supply; through competition for labor or market share; or due to shifts to alternate inputs as a result of price or regulatory changes."

In addition to this it may be necessary to single out economic interdependencies as a specific type, or at least sub-type of logical interdependencies. These are relationships between infrastructures or infrastructure components which exist through some financial mechanism. This is particularly important when considering the financing of infrastructure projects, or the extraction of value during the operational phase. Another type of economic interdependency may be budgetary interdependencies (Friesz et al., 2007) where infrastructures are funded by the same source and therefore the delivery or condition of one may be impacted by the other.

The UK's 2011 National Infrastructure Plan (HM Treasury and Infrastructure UK, 2011) outlines three forms of interdependencies (p90):

- geographic co-location

- $\quad$ shared use (of equipment or resource)

- reliance on another network's function.

While this aligns with the split into geographic and functional, shared use expands on the previous conception of physical interdependencies. A Frontier Economics (2012) report implements a definition of interdependency proposed by O'Rourke (2007), which suggests that it results from physical proximity or operational interaction, reflecting the two-factor split into spatial and functional interdependency. They use this to develop an economic framework within which to consider interdependency, which proposes three forms: physical, digital, and organisational (e.g. shared ownership or oversight). 
The division was made slightly differently by Wallace et al. (2003) who along with co-location, used input (a functional dependency where a system depends on an input from another); shared (where two or more infrastructures use the same asset or service), and; exclusive-or (whereby two infrastructure systems require the same limited resource which can only be used by one at a time as suggested may exist in the topology represented in Figure 6 and in market and spatial economic competition). These have been echoed by views of infrastructure as a system of systems (Eusgeld et al., 2011).

Despite the influence of Rinaldi et al. there is still a lack of high-level framework for characterising the complexity of all types of infrastructure interdependency (Haimes, 2005; Satumtira and Duenas-Osorio, 2010), the technical understanding of which is in its infancy (Chang, 2010). A recent analysis (Ouyang, 2014) of the taxonomies of Rinaldi et al. (2001), Zimmerman (2001), Dudenhoeffer et al. (2006), Wallace et al. (2003) and Zhang and Peeta (2011) concluded that "some interdependency examples in practice cannot be definitely categorized by some classifications", and only the classification proposed by Rinaldi et al. (2001) covered all ten real-world interdependency examples analysed.

\subsection{Interaction type}

Raven and Verbong (2007) identified four types of interaction from their analysis of Dutch combined heat and power plants, which they refer to as a type of socio-technical regime. As these relate directly to infrastructure, it is important they are considered in the description of forms of interdependency. The four types are:

- competition (two elements or systems perform similar functions, or as an extension of this, fulfil a similar need)

- symbiosis (two elements or systems mutually benefit from co-operation which could, they note, be in the form of long term-supply contracts)

- integration (two elements or system operate as one, potentially through shared ownership, actors or technologies)

- spill over (the rules or models of operation from one element or system are recreated in another, connecting them through common operational or cognitive modes and behavioural norms).

The first three are ordered in terms of the increasing amount of co-operation they involve between the interacting elements, while the fourth is more indirect. These are distinct from the more common typologies described in the previous section, and are not explicitly described as a means to characterise interdependency, though there is clearly some overlap. A physical interaction could then be further characterised using these classifications, but it might be harder to similarly characterise a geographic co-location. Symbiosis aligns with what is seemingly the most common understanding of interdependency, as Raven and Verbong witnessed it in terms of a mutual input-output dependency.

Along similar lines to these, Friesz et al. (2007) have also suggested market interdependencies and spatial economic competition whereby goods and services exchanged over infrastructures are part of a single market and can therefore influence each other. 


\subsection{Functionality}

The next two characteristics of functionality and necessity should be considered in combination. The distinction they make is important, but often overlooked.

Zimmerman (Zimmerman and Restrepo, 2006; Zimmerman, 2001), looking specifically at infrastructure interdependency differentiates between two types functional and spatial. Elsewhere he has used geographic/spatial/physical to all mean collocated infrastructures, functional to mean a reliance on each other to operate, and economic to represent dependence on another infrastructure as a source or recipient of goods and services (Zimmerman, 2006). Others using similar distinctions suggest functional (covering physical, cyber and logical relationships) and geographic (Johansson and Hassel, 2010) or; functional (referring to input-output relationships) and structural (where two operational regimes conjointly use the same technical or social elements) relationships (Konrad et al., 2008).

On the surface these may seem like a less nuanced version of the more common four-factor typology proposed by Rinaldi et al., however it is the distinction between functional and non-functional relationships which is important. Without it, it is all too easy to assume that interdependent infrastructures must rely on each other in a functionally necessary way and any other type of relationship is not an interdependency.

In practice interdependency is not synonymous with functionally necessary interdependency, the reality is far more complex. In terms of vulnerability analysis, functional dependency between two elements can be of utmost importance, but in terms of opportunities and efficiencies, the creation of non-functional interdependencies can be significant. While describing infrastructure interdependency as "a bidirectional relationship in which the output of one is essential as the input of another", Chou and Tseng (2010) also offer the following example:
"if a gas pipeline leaks and subsequent explosion occurs, which damages a nearby telecommunication facility, the emergency information could not be efficiently relayed, and the subsequent fire may be worse with more damage to the gas system than if help is more promptly dispatched, possibly preventing further damage to the telecommunication facility."

In this example the gas system depends on the service which forms an output of the telecommunication system, but the telecommunication system only depends on an output of the gas system if 'not exploding' is considered an output of that system. Arguably, safe operation would be a requirement of the gas system in some respect, but it would appear different enough to the notion of an output to require a richer definition of interdependency.

The ElecLink Channel Tunnel Interconnector has been said to create a geographic interdependency saving in the region of $£ 60 \mathrm{~m}$ compared to laying a seabed cable (Frontier Economics, 2012). The Channel Tunnel Rail link does not depend on the electricity interconnector for it to function, and the interconnector does not depend on the functioning of the rail link. Another example could include two infrastructure systems in some form of competition. The performance of one may affect demand for the other, but they are not functionally dependent upon one another. 


\subsection{Necessity}

Even if a functional relationship exists it may not actually be necessary to the operation of either element, indeed during the design stage it may be optional as to whether the interdependency is created or exploited to provide additional benefits such as enhanced efficiency or resilience. This addition arose from work looking to identify beneficial interdependency opportunities in three UK case studies (Rosenberg and Carhart, 2013). It is particularly useful if seeking to consider actual and hypothetical interdependencies.

This distinction may present semantic problems as if one system depends on another, then it could be argued that that relationship is almost tautologically necessary. However, this argument does not stand if one accepts the previous distinction between functional and non-functional interdependencies.

The previous two dimensions can be combined to produce four distinct types as shown in Figure 7.

Figure 7 Functionality and necessity matrix

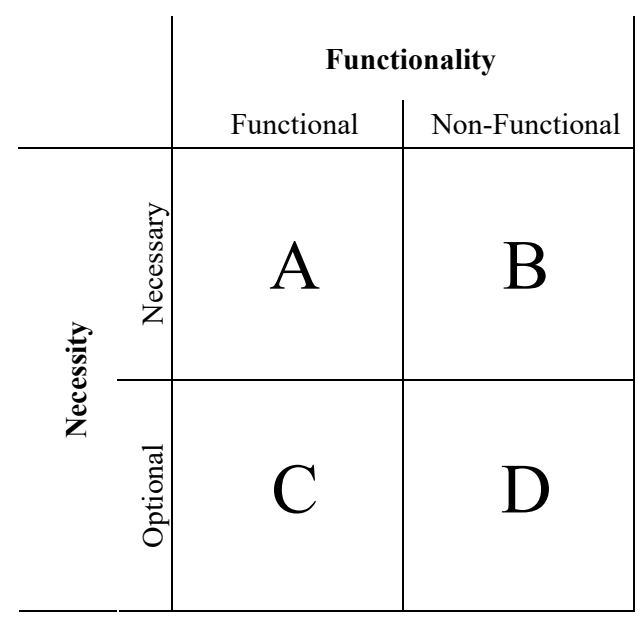

Quadrant A represents a type of relationship which is both functional and necessary. This would fit most closely with a literal interpretation of dependency. For example a water treatment plant requires electricity in order for it to perform its primary function. It would also be true to say that electricity provides a necessary function to the water treatment plant.

Quadrant B represents a type of relationship that is necessary, but is not functional in nature. For example, due to spatial restrictions it may be unavoidable that two separate infrastructure assets are located in the same physical space. Neither provides a function to the other, neither depends on the other for them to fulfil their purpose. It is worth noting that the location of the relationship within these quadrants may be dynamic; that is to say two systems may be functionally independent under normal circumstances, but this may change in specific scenarios (or indeed vice-versa). This is particularly relevant when considering states of failure or degradation, and the risk and resilience of the systems involved. 
Quadrant C represents a type of relationship which is functional, but optional. This could be because one element provides a back-up or substitute function to another, a function that is already primarily served by another system. Losing this substitute does not affect the system's ability to fulfil its purpose. It may be that this relationship already exists, or perhaps it is important to highlight that this relationship could exist. Smart meters provide additional functionality to the grid, but this could be considered an optional function as the grid could fulfil its purpose without them.

Quadrant D represents an optional, non-functional relationship. An example of this might be when two infrastructure systems which could be located in the same physical space in order to improve efficiency. Another example would be when the same infrastructure service could be fulfilled by the same organisation. Interdependencies in this quadrant are particularly interesting as they would be of little interest, and frequently overlooked, under the traditional infrastructure interdependency focus of risks and hazards.

\subsection{Outcome}

When considering the design of interdependencies into a system it is particularly useful to capture whether they ultimately provide a benefit or an opportunity to benefit the system, or whether they result in an increase in hazardous dis-benefit. If it is beneficial then there may be a reason to utilise an existing interdependency and leverage it for additional value or alternatively create it if there is the potential to do so. If it is ultimately affecting the risk profile in a negative way, there may be a reason to mitigate, replace or prevent the interdependency from existing. As with upstream/downstream characterisation the outcome may be subjective to the particular component or system of interest. An interdependency linking system A with system B may create benefits for system A or at the system-of-systems level, while having dis-benefits on system B. Again, there may be a temporal dimension to this as additional values result from the coevolution of purposefully engineered interdependnecy.

\subsection{Life-cycle impact stage}

This refers to the chronological phase of the infrastructure's life cycle during which the interdependency exists or its impact is felt. Some interdependencies only have an impact or are only relevant during the planning or construction phase, others are important during operation or at the infrastructure element's 'end of life'. Additionally, some interdependencies are only relevant under particular scenarios (such as during accidental failure or during extreme weather events). These categories also arose during the research of three UK case studies (Rosenberg and Carhart, 2013). For example over 4 million tonnes of material excavated during the construction phase of the London Crossrail project was used to create a wetland nature reserve at Wallasea Island (2012). As with many of the other characteristic, these categories are not necessarily mutually exclusive and depend largely on perspective and system of interest. The chains from Isambard Kingdom Brunel's original Hungerford Bridge over the River Thames, were removed in 1860 and reused in the stalled construction of the Clifton Suspension Bridge. The availability of these chains at low cost enabled John Hawkshaw to develop a sound business case for the completion, something that had previously been problematic 
(Portman, 2002). This could be considered both an end of life and construction phase interdependency.

\subsection{Geographic scale}

Identifying whether the interdependency exists on a local, regional, national or international scale may be important, as may characterising where the impact of the interdependency lies (McDaniels et al., 2007; Peerenboom, 2001). It is also suggested that it could also be considered whether the interdependency is constrained within a single project, which could be considered sub-local, or in combination with the other three geographic scale characteristics.

\subsection{Sectoral scale}

In addition to the geographic scale over which the interdependency sits, it may also be useful to make the distinction between those interdependencies that exist between elements within one particular sector (intra-sector interdependencies) such as the provision of electricity to run services within a power station, or those which extend between elements in different sectors (inter-sector interdependencies), such as the provision of electricity to run a water processing facility. Table 1 compiles a checklist of interdependency categories described above.

Table 1 Infrastructure interdependency characterisation checklist

\begin{tabular}{|c|c|c|c|}
\hline & & & $\begin{array}{c}\text { Identified } \\
\text { interdependency }\end{array}$ \\
\hline \multirow[t]{2}{*}{ DIRECTIONALITY } & \multirow{2}{*}{$\begin{array}{l}\text { Whether the reliance of one } \\
\text { element on another is mutual }\end{array}$} & Bi-directional & \\
\hline & & Non-reciprocal & \\
\hline \multirow[t]{3}{*}{ ORDER* } & \multirow{3}{*}{$\begin{array}{l}\text { Whether the relationship is } \\
\text { direct or via an intermediary. }\end{array}$} & First order & \\
\hline & & Second order & \\
\hline & & Higher order & \\
\hline \multirow[t]{2}{*}{ COUPLING } & \multirow{2}{*}{$\begin{array}{l}\text { Whether the effects of the } \\
\text { relationship are felt closely } \\
\text { in time and space or not. }\end{array}$} & Loose & \\
\hline & & Tight & \\
\hline \multirow[t]{2}{*}{ LOCATION* } & \multirow{2}{*}{$\begin{array}{l}\text { Whether the element of interest } \\
\text { provides or receives a resource. }\end{array}$} & Upstream & \\
\hline & & Downstream & \\
\hline \multirow[t]{4}{*}{ TYPE } & \multirow{4}{*}{$\begin{array}{l}\text { The nature of the relationship, } \\
\text { spatially or in terms of resource flow. }\end{array}$} & Physical & \\
\hline & & Digital & \\
\hline & & Geographic & \\
\hline & & Organisational & \\
\hline \multirow{4}{*}{$\begin{array}{l}\text { INTERACTION } \\
\text { TYPE }\end{array}$} & \multirow{4}{*}{$\begin{array}{l}\text { The degree of co-operation and } \\
\text { structure of the relationship. }\end{array}$} & Competition & \\
\hline & & Symbiosis & \\
\hline & & Integration & \\
\hline & & Spill over & \\
\hline
\end{tabular}

Note: *Require explicit specification of system/element of interest from which the perspective is taken. 
Table 1 Infrastructure interdependency characterisation checklist (continued)

\begin{tabular}{|c|c|c|c|}
\hline & & & $\begin{array}{c}\text { Identified } \\
\text { interdependency }\end{array}$ \\
\hline FUNCTIONALITY & $\begin{array}{l}\text { Whether the relationship is an } \\
\text { integral part of the function of the } \\
\text { elements or not. }\end{array}$ & $\begin{array}{l}\text { Functional } \\
\text { Non-functional }\end{array}$ & \\
\hline NECESSITY* & $\begin{array}{l}\text { Whether the relationship is } \\
\text { unavoidable or required, or } \\
\text { whether there is flexibility. }\end{array}$ & $\begin{array}{l}\text { Necessary } \\
\text { Optional }\end{array}$ & \\
\hline OUTCOME* & $\begin{array}{l}\text { Whether the effect of the relationship } \\
\text { on the element of interest in positive } \\
\text { or negative. }\end{array}$ & $\begin{array}{l}\text { Benefit } \\
\text { Dis-benefit }\end{array}$ & \\
\hline $\begin{array}{l}\text { LIFE-CYCLE } \\
\text { IMPACT STAGE }\end{array}$ & $\begin{array}{l}\text { The phase of the project during } \\
\text { which the effects of the relationship } \\
\text { are relevant. }\end{array}$ & $\begin{array}{l}\text { Planning } \\
\text { Construction } \\
\text { Operation } \\
\text { End of life } \\
\text { Scenario }\end{array}$ & \\
\hline $\begin{array}{l}\text { GEOGRAPHIC } \\
\text { SCALE }\end{array}$ & $\begin{array}{l}\text { The spatial distribution of the } \\
\text { relationship or its effects. }\end{array}$ & $\begin{array}{l}\text { Project } \\
\text { Local } \\
\text { National } \\
\text { International }\end{array}$ & \\
\hline $\begin{array}{l}\text { SECTORAL } \\
\text { SCALE }\end{array}$ & $\begin{array}{l}\text { Whether the relationship is } \\
\text { contained within one infrastructure } \\
\text { sector or not. }\end{array}$ & $\begin{array}{l}\text { Intra-sector } \\
\text { Inter-sector }\end{array}$ & \\
\hline
\end{tabular}

Note: *Require explicit specification of system/element of interest from which the perspective is taken.

While the taxonomy above has focused on the characteristics of the relationships between infrastructure elements, it may also be useful to further develop those that characterise the context within which the relationship sits, and to provide further dimensions through which to describe the potential outcomes the relationship may have. Five such dimensions have been suggested by Rinaldi et al. (2001): infrastructure environment; response behaviour; infrastructure characteristics; types of failure, and; state of operations. McDaniels et al. (2007) suggest further categories by studying examples of interdependency captured in failure reports. These include: impacted system (e.g. education, emergency services, food supply etc.); type of infrastructure failure interdependency (cascading, escalation, restoration, compound damage propagation or substitutive); the resulting system failure; the operational state of the impacted system; the adaptive potential of the impacted system; restart time of the impacted system; severity of impact; spatial extent of impact; number of people affected by the failure, and; duration of the consequences. These are all clearly relevant when attempting to describe the impact of interdependencies on vulnerability and failure, but are less relevant for the consideration of the ontology of interdependencies as is the concern here. There is an opportunity therefore to further develop the description of interdependencies and their impacts in terms of proactively identifying them and their positive values. 


\section{Case study application - UK infrastructure timelines}

Engineering the Future is an alliance of the Engineering Council, Engineering UK, the Institution of Chemical Engineers, the Institution of Civil Engineer, the Institution of Engineering and Technology, the Institution of Mechanic Engineers, the Institute of Physics and The Royal Academy of Engineering. It has produced a set of parallel timelines to capture the next 40 years of UK infrastructure planning across five infrastructure sectors (energy, ICT, transportation, waste, water). This useful visualisation documents the known policies and plans in these sectors, together with expert opinion of future policies and projects from the engineering community (Engineering the Future, 2011).

A workshop was held which brought together 25 infrastructure stakeholders from across the five timeline sectors in order to identify potentially beneficial interdependencies between the future policies and projects captured in the timelines (The Systems Centre, University of Bristol, 2013). This included representation from industry and academia, as well as those involved with the governance of the UK's infrastructure. The technical details of the identified interdependencies are reported elsewhere (Engineering the Future, 2013), while this section specifically describes the application of the taxonomy proposed above to the identified interdependencies.

The workshop put into practice the interdependency planning and management framework (Carhart et al., 2014; Rosenberg and Carhart, 2013), in particular operationalising a matrix-based tool for interdependency identification and knowledge structuring. The workshop consisted of two sessions. During the first session stakeholders from a single sector sought to identify potentially beneficial interdependencies between projects and policies within that sector, while during the second session, inter-sector interdependencies were identified. It is important to note, that in terms of the characterisation criteria, the participants in this application were asked to actively seek beneficial interdependencies that were either under-exploited or not being exploited at all and therefore could be classed as optional. The results reflect this accordingly.

During the first session key policies and projects were placed into boxes along the leading diagonal of a blank matrix. The participants systematically populated the off-diagonal spaces with details of the interactions between them. They were encouraged to characterise these relationships as much as possible. The second session saw interdisciplinary groups complete a pre-formatted matrix with the five infrastructure sectors along the leading diagonal, identifying, recording and characterising the inter-sector interdependencies between the projects and policies used in the first session. It is not suggested that the interdependencies identified during this exercise form an exhaustive list, but they nevertheless represent a sample of those felt to be prominent amongst the gathered industry experts.

\subsection{Intra-sector interdependencies}

A total of 77 intra-sector interdependencies were identified during the first session. The breakdown per sector is shown in Table 2 . 
Table 2 Case study intra-sector relationship opportunities identified by sector

\begin{tabular}{lc}
\hline Sector & Intra-sector relationships \\
\hline Energy & 27 \\
Transport & 11 \\
ICT & 11 \\
Waste & 3 \\
Water & 25 \\
\hline Total & 77 \\
\hline
\end{tabular}

Due to the spread of expertise available during the workshop the waste and ICT sectors prepared a joint interdependency matrix during the first session, resulting in the identification of an additional 11 potential interdependencies which crossed between the two sectors.

Each interdependency has been identified from the perspective of a specific sector or project and is evaluated accordingly. This means that an interdependency identified as presenting a hazard or dis-benefit may actually be beneficial to an external actor or system.

The results are summarised in Table 3 along with those for the identified inter-sector relationships. Some characteristics are omitted where they do not make sense out of their specific context (e.g. location), the wider context (e.g. order) or there was insufficient information (e.g. coupling).

Table 3 Case study intra-sector and inter-sector relationship characteristics

\begin{tabular}{llcc}
\hline & & $\begin{array}{c}\text { Intra-sector } \\
(n=77)\end{array}$ & $\begin{array}{c}\text { Inter-sector } \\
(n=69)\end{array}$ \\
\hline DIRECTIONALITY & Bi-directional & $42 \%(32)$ & $30 \%(21)$ \\
TYPE & Non-reciprocal & $58 \%(45)$ & $70 \%(48)$ \\
& Physical & $43 \%(33)$ & $45 \%(31)$ \\
& Digital & $16 \%(12)$ & $13 \%(9)$ \\
GNTERACTION TYPE & Oeographic & $14 \%(11)$ & $13 \%(9)$ \\
& Companisational & $27 \%(21)$ & $29 \%(20)$ \\
& Symbiosis & $3 \%(2)$ & $2 \%(1)$ \\
FUNCTIONALITY & Integration & $69 \%(53)$ & $78 \%(54)$ \\
& Spill over & $9 \%(7)$ & $17 \%(12)$ \\
& Integration and spill-over & $1 \% \%(14)$ & $3 \%(2)$ \\
NECESSITY* & Functional & $58 \%(45)$ & $55 \%(38)$ \\
& Non-functional & $42 \%(32)$ & $45 \%(31)$ \\
& Necessary & $26 \%(20)$ & $39 \%(27)$ \\
& Optional & $74 \%(57)$ & $61 \%(42)$ \\
\hline
\end{tabular}

Note: *Require explicit specification of system/element of interest from which the perspective is taken. 
Table 3 Case study intra-sector and inter-sector relationship characteristics (continued)

\begin{tabular}{|c|c|c|c|}
\hline & & $\begin{array}{c}\text { Intra-sector } \\
(n=77)\end{array}$ & $\begin{array}{l}\text { Inter-sector } \\
\quad(n=69)\end{array}$ \\
\hline \multirow[t]{2}{*}{ OUTCOME* } & Benefit & $87 \%(67)$ & $86 \%(59)$ \\
\hline & Dis-benefit & $13 \%(10)$ & $14 \%(10)$ \\
\hline \multirow[t]{9}{*}{ LIFE-CYCLE IMPACT STAGE } & Planning & $4 \%(3)$ & $0 \%(0)$ \\
\hline & Construction & $0 \%(0)$ & $0 \%(0)$ \\
\hline & Operation & $90 \%(69)$ & $91 \%(63)$ \\
\hline & End of life & $0 \%(0)$ & $0 \%(0)$ \\
\hline & Scenario & $3 \%(2)$ & $0 \%(0)$ \\
\hline & Planning and operation & $0 \%(0)$ & $2 \%(1)$ \\
\hline & Construction and operation & $0 \%(0)$ & $2 \%(1)$ \\
\hline & Operation and scenario & $0 \%(0)$ & $6 \%(4)$ \\
\hline & Planning - end of life & $4 \%(3)$ & $0 \%(0)$ \\
\hline \multirow[t]{10}{*}{ GEOGRAPHIC SCALE } & Project & $29 \%(22)$ & $13 \%(9)$ \\
\hline & Local & $23 \%(18)$ & $3 \%(2)$ \\
\hline & National & $19 \%(15)$ & $36 \%(25)$ \\
\hline & International & $5 \%(4)$ & $0 \%(0)$ \\
\hline & Project and local & $8 \%(6)$ & $9 \%(6)$ \\
\hline & Project and national & $6 \%(5)$ & $0 \%(0)$ \\
\hline & Project to national & $4 \%(3)$ & $23 \%(16)$ \\
\hline & Local to national & $3 \%(2)$ & $13 \%(9)$ \\
\hline & National and international & $0 \%(0)$ & $3 \%(2)$ \\
\hline & Project to international & $3 \%(2)$ & $0 \%(0)$ \\
\hline
\end{tabular}

Note: *Require explicit specification of system/element of interest from which the perspective is taken.

As expected, necessity and outcome reported a high number of optional and beneficial relationships by virtue of the workshops stated objective of identifying potential interdependencies which would have a positive impact.

Within impact stage, while specific flooding scenarios were discussed, these were attributed to the 'operation' phase as they were only discussed in relation to flood defence infrastructures.

The characterisation of $69 \%$ of the identified interdependency opportunities as symbiotic makes assumptions about the projects or assets not being owned by the same organisation. For example, it assumed that the organisations involved in internet-of-things assets are distinct from internet service providers and those who own the communications infrastructure on which it operates.

Table 4 shows the distribution of necessity and functionality amongst the identified interdependencies. It further illustrates the existence of necessary but non-functional interdependencies as well as optional functional ones. 
Table 4 Intra-sector necessity-functionality distribution

\begin{tabular}{|c|c|c|c|}
\hline & & \multicolumn{2}{|c|}{ Functionality } \\
\hline & & Functional & Non-functional \\
\hline \multirow{2}{*}{ 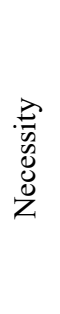 } & 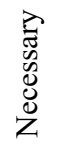 & $\begin{array}{l}16 \% \\
(12)\end{array}$ & $\begin{array}{c}10 \% \\
(8)\end{array}$ \\
\hline & 胥 & $\begin{array}{l}43 \% \\
(33)\end{array}$ & $\begin{array}{l}31 \% \\
(24)\end{array}$ \\
\hline
\end{tabular}

Simplified examples of those identified in each quadrant include:

- necessary and functional: ICT networks provide basis for internet of things tagging initiatives

- necessary and non-functional: Smart grid advances will influence the location and nature of local gas facilities

- optional and functional: Smart meters providing energy use information back to the grid

- Optional and non-functional: collaboration between South East Airport Capacity and Rail projects to create an interdependent business case.

\subsection{Inter-sector interdependencies}

In total 69 inter-sector relationships were identified. Table 5 shows the distribution of these relationships in terms of the sectors they connect. For example, eight connections were identified between projects and policies in the Energy and ICT sectors, three of these were initially identified as outputs of the Energy sector to the ICT sector, while five were identified as outputs of the ICT sector providing resources to the Energy sector. Further analysis revealed that some of these were bi-directional relationships such as co-located assets.

Table 5 Inter-sector interdependency locations

\begin{tabular}{ccccc}
\hline Energy & 3 & 3 & 2 & 4 \\
5 & ICT & 8 & 3 & 4 \\
7 & 2 & Transport & 3 & 4 \\
3 & 0 & 4 & Waste & 3 \\
5 & 2 & 4 & 0 & Water \\
\hline
\end{tabular}

The characterisation of these largely beneficial, under or un-exploited interdependencies are shown in Table 3. As with the intra-sector interdependencies, the vast majority of those identified existed during the operational phase of the infrastructure, as physical interdependencies forming a symbiotic relationship. The spread of both type and interaction type were similar across both the intra- and inter-sector datasets. The 
identified interdependencies tended to operate over a more national scale than the local or project orientated intra-sector interdependencies.

The prevalence of a particular type of interdependency identified in these sets may result from the prevalence of particular approaches such as input-output models (Satumitra and Duenas-Osorio, 2010) which only capture physical and digital interdependencies (Ouyang, 2014). This may result in increased awareness of some types over others.

The split between functional and non-functional interdependencies is relatively similar to the intra-sector analysis. It does not necessarily follow that the split between the two is so even in reality as the workshops objective to identify optional beneficial interdependencies would mean the majority of known interdependencies providing necessary functions would be considered beyond the scope of the exercise unless they were being underexploited in some way.

The distribution of necessity and functionality is however quite different between the two sets as shown in Table 6. Far more functional and necessary interdependencies were identified, while the optional interdependencies are marginally more skewed towards non-functional relationships. This again suggests that it is important to consider these non-functional interdependencies when actively seeking those which are unexploited or under exploited and from which additional value could be extracted.

Table 6 Inter-sector necessity-functionality distribution

\begin{tabular}{|c|c|c|c|}
\hline & & \multicolumn{2}{|c|}{ Functionality } \\
\hline & & Functional & Non-functional \\
\hline \multirow{2}{*}{ 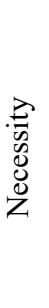 } & $\begin{array}{l}\vec{Z} \\
\text { W } \\
\delta \\
0 \\
\mathbb{D} \\
Z\end{array}$ & $\begin{array}{l}30 \% \\
(21)\end{array}$ & $\begin{array}{l}9 \% \\
(6)\end{array}$ \\
\hline & 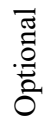 & $\begin{array}{l}25 \% \\
(17)\end{array}$ & $\begin{array}{l}36 \% \\
(25)\end{array}$ \\
\hline
\end{tabular}

Simplified examples of those identified in each quadrant include:

\begin{tabular}{ll}
\hline Necessary and functional & $\begin{array}{l}\text { Energy sector provides electricity for operating and } \\
\text { cooling ICT sector assets. }\end{array}$ \\
Necessary and non-functional & $\begin{array}{l}\text { Energy sector requires payment from ICT sector for } \\
\text { provision of electricity. }\end{array}$ \\
Optional and functional & $\begin{array}{l}\text { By-products from the Waste sector could be used as a resource } \\
\text { input to the Energy sector for processes such as anaerobic } \\
\text { digestion. }\end{array}$ \\
Optional and non-functional & $\begin{array}{l}\text { Co-location opportunities of some ICT sector assets } \\
\text { (e.g. telecoms cables) with planned Transport sector assets. }\end{array}$ \\
\hline
\end{tabular}




\section{Conclusions}

Collating the terminology used in the description of infrastructure interdependency modelling, and developing it with additional characteristics was found to be useful in the practical search for interdependency opportunities, and is an important first stage in the establishment of a meta-framework for coherently and completely discussing, characterising and modelling infrastructure interdependency across infrastructure sectors and amongst different disciplines. It has been shown that there are many different dimensions to infrastructure interdependency both in theory and in practice. It is hoped that this will initiate, extend and formalise further discussion on the nature of infrastructure interdependency and ultimately aid in facilitating cross-sector discussions. Without a common language with which to describe all aspects of interdependency there is a danger that an important piece of the puzzle will be overlooked. It would also appear particularly important to consider non-functional interdependencies when actively seeking opportunities from infrastructure interdependency.

The viewpoints and perspectives of the different stakeholders (e.g. users and operators) within different sectors and at different layers of the socio-technical system should also not be overlooked. The same interdependency may be described and valued differently by different groups. This further reinforces the need for a robust framework within which to characterise interdependency. So far, this has consciously focused on qualitative distinctions between different interdependency characteristics in order to promote greater consideration for the sorts of interdependencies that seem to be largely overlooked, and the need for different approaches to understand them structurally.

A rich and shared through-life understanding of the diverse aspects of infrastructure interdependency, and an appreciation for which modelling tools best represent each of those aspects, are fundamental to creating a framework to integrate toolsets and provide a more comprehensive picture of the interdependencies in the infrastructure 'system-ofsystems'. This has implications for the design of infrastructure assets and their integration in the wider network of a nation's infrastructure, by helping to minimise unforeseen vulnerabilities and maximise opportunity management for valuable emergent economic and social benefits that might otherwise by missed. Multiple modelling approaches are required to effectively capture the emergent properties of all of the different characteristics of the relationships between infrastructure systems. Such a framework assists in bringing these models together in a coherent way.

\section{References}

Bloomfield, R., Salako, K., Wright, D., Chozos, N. and Nobles, P. (2009) Infrastructure Interdependency Analysis: An Introductory Research Review, City University London, London, UK.

Brown, T. (2008) 'Infrastructure dependency indicators', Wiley Handbook of Science and Technology for Homeland Security, John Wiley \& Sons, Inc., Hoboken, NJ, USA.

Carhart, N., Rosenberg, G., Edkins, A., Ward, E. and Dean, M. (2014) A Proposed Interdependency Planning and Management Framework: Development and Application for UK Infrastructure, UCL, London, UK.

Chang, S. (2010) 'Infrastructure resilience to disasters', Frontiers of Engineering:: Reports on Leading-Edge Engineering from the 2009 Symposium, p.176, National Academies Press, Washington D.C., USA. 
Chou, C-C. and Tseng, S-M. (2010) 'Collection and analysis of critical infrastructure interdependency relationships', J. Comput. Civ. Eng., Vol. 24, No. 6, pp.539-547.

Department of Defense (2009) Department of Defense Architecture Framework Version 2.0.

Dudenhoeffer, D., Permann, M. and Manic, M. (2006) 'CIMS: a framework for infrastructure interdependency modeling and analysis', Proceedings of the 2006 Winter Simulation Conference, IEEE, pp.478-485.

Endsley, M.R. (1995) 'Toward a theory of situation awareness in dynamic systems', Hum. Factors J. Hum. Factors Ergon. Soc., Vol. 37, No. 1, pp.32-64.

Engineering the Future (2011) UK Infrastructure Timelines.

Engineering the Future (2013) Infrastructure Interdependencies Timelines.

Eusgeld, I., Nan, C. and Dietz, S. (2011) “"System-of-systems” approach for interdependent critical infrastructures', Reliab. Eng. Syst. Saf., Vol. 96, No. 6, pp.679-686.

Friesz, T.L., Mookherjee, R. and Peeta, S. (2007) 'Modeling large scale and complex infrastructure systems as computable games', in Friesz, T.L. (Ed.): Network Science, Nonlinear Science and Infrastructure Systems, International Series in Operations Research \& Management Science, pp.53-75, Springer US, Boston, MA.

Frontier Economics (2012) Systemic Risks and Opportunities in UK Infrastructure - A Report Prepared for HM Treasury \& Infrastructure UK.

Google Books Ngram [WWW Document] (2015) [online] http://books.google.com/ngrams (accessed 3 February 2015).

Haimes, Y.Y. (2005) 'Infrastructure interdependencies and homeland security', J. Infrastruct. Syst., Vol. 11, No. 2, pp.65-66.

Heller, M. (2002) 'Interdependencies in civil infrastructure systems', Frontiers of Engineering: Reports on Leading-Edge Engineering from the 2001 NAE Symposium on Frontiers of Engineering, p.138, National Academies Press, Washington D.C., USA.

HM Government Cabinet Office (2011) Keeping the Country Running: Natural Hazards and Infrasructure - A Guide to Improving the Resilience of Critical Infrastructure and Essential Services, London, UK.

HM Treasury and Infrastructure UK (2011) National Infrastructure Plan 2011.

Huang, C-N., Liou, J.J.H. and Chuang, Y-C. (2014) 'A method for exploring the interdependencies and importance of critical infrastructures', Knowledge-Based Syst., Vol. 55, pp.66-74.

Johansson, J. and Hassel, H. (2010) 'An approach for modelling interdependent infrastructures in the context of vulnerability analysis', Reliab. Eng. Syst. Saf., Vol. 95, No. 12, pp.1335-1344.

Konrad, K., Truffer, B. and Voß, J-P. (2008) 'Multi-regime dynamics in the analysis of sectoral transformation potentials: evidence from German utility sectors', J. Clean. Prod., Vol. 16, No. 11, pp.1190-1202.

Kruchten, P. (1995) 'Architectural blueprints - the " $4+1$ " view model of software architecture', IEEE Softw., Vol. 12, No. 6, pp.42-50.

Laprie, J-C., Kanoun, K. and Kaaniche, M. (2007) 'Modelling interdependencies between the electricity and information infrastructures', in Saglietti, F. and Oster, N. (Eds.): Computer Safety, Reliability, and Security, Lecture Notes in Computer Science, Springer, Berlin, Heidelberg, pp.54-67.

Little, R.G. (2002) 'Controlling cascading failure: understanding the vulnerabilities of interconnected infrastructures', J. Urban Technol., Vol. 9, No. 1, pp.109-123.

McDaniels, T., Chang, S., Peterson, K., Mikawoz, J. and Reed, D. (2007) 'Empirical framework for characterizing infrastructure failure interdependencies', J. Infrastruct. Syst., Vol. 13, No. 3, pp.175-184.

Michel, J-B., Shen, Y.K., Aiden, A.P., Veres, A., Gray, M.K., Pickett, J.P., Hoiberg, D., Clancy, D., Norvig, P., Orwant, J., Pinker, S., Nowak, M.A. and Aiden, E.L. (2011) 'Quantitative analysis of culture using millions of digitized books', Science, Vol. 331, No. 6014, pp.176-82. 
O’Rourke, T.D. (2007) 'Critical infrastructure, interdependencies, and resilience', Bridg., Vol. 37, No. 1, pp.22-29.

OED Online (2015) Interdependence, $\mathrm{n}$ [WWW Document], Oxford English Dict. [online] http://www.oed.com/view/Entry/97699?rskey=HbNm13\&result=1 (accessed 3 February 2015).

Ouyang, M. (2014) 'Review on modeling and simulation of interdependent critical infrastructure systems', Reliab. Eng. Syst. Saf., Vol. 121, pp.43-60.

Pederson, P., Dudenhoeffer, D., Hartley, S. and Permann, M. (2006) Critical Infratructure Interdependency Modeling: A Survey of U.S. and International Research, Idaho National Laboratory, Idaho Falls, Idaho, USA.

Peerenboom, J.P. (2001) 'Infrastructure interdependencies: overview of concepts and terminology', National Science Foundation/Office of Science and Technology Policy Workshop on Critical Infrastructure Needs in Interdisicplinary Research and Graduate Training.

Perrow, C. (1984) Normal Accidents, Basic Books, New York.

Pimmler, T. and Eppinger, S. (1994) 'Integration analysis of product decompositions', ASME 6th International Conference on Design Theory and Methodology.

Portman, D. (2002) 'A business history of the Clifton Suspension Bridge', Constr. Hist., Vol. 18, pp.3-20.

Raven, R. and Verbong, G. (2007) 'Multi-regime interactions in the Dutch energy sector: the case of combined heat and power technologies in the Netherlands 1970-2000', Technol. Anal. Strateg. Manag., Vol. 19, No. 4, pp.491-507.

Rinaldi, S.M., Peerenboom, J.P. and Kelly, T.K. (2001) 'Identifying, understanding, and analyzing critical infrastructure interdependencies', IEEE Control Syst. Mag., Vol. 21, No. 6, pp.11-25.

Rosenberg, G. and Carhart, N.J. (2013) 'A systems-based approach to creating value from infrastructure interdependencies', International Symposium for Next Generation Infrastructure, Wollongong.

Satumtira, G. and Duenas-Osorio, L. (2010) 'Synthesis of modeling and simulation methods on critical infrastructure interdependencies research', in Gopalakrishnan, K. and Peeta, S. (Eds.): Sustainable and Resilient Critical Infrastructure Systems: Simulation, Modeling, and Intelligent Engineering, p.300, Springer, Berlin, Germany.

The Clinton Administration (1998) Presidential Directive 63 (PDD-63): Policy on Critical Infrastructure Protection.

The Royal Academy of Engineering (2007) Creating Systems that Work: Principles of Engineering Systems for the 21st Century.

The Systems Centre, University of Bristol (2013) Workshop Application of a Matrix Based Approach to the Identification of Infrastructure Interdependencies - Workshop Report for Engineering the Future.

TRAK Steering Group and Department for Transport (2013) TRAK Enterprise Architecture Framework.

Wallace, W.A., Mendonça, D., Lee, E.E., Mitchell, J.E. and Chow, J.H. (2003) 'Managing disruptions to critical interdependent infrastructure in the context of the 2001 World Trade Centre Attack', in Monday, J.L. (Ed.): Beyond September 11th: An Account of Post-Disaster Research, p.600, Natural Hazards Research and Applications Information Center, Boulder, $\mathrm{CO}$, USA.

Wallasea Island (2012) Wallasea Island Jetty Completed as Crossrail Helps RSPB Shape Europe's Largest New Nature Reserve - Crossrail [WWW Document] [online] http://www.crossrail. co.uk/news/articles/wallasea-isl-jetty-completed-as-crossrail-helps-rspb-shape-europeslargest-new-nature-reserve (accessed 19 May 2015).

Zachman, J.A. (1987) 'A framework for information systems architecture', IBM Syst. J., Vol. 26, No. 3, pp.276-292.

Zhang, P. and Peeta, S. (2011) 'A generalized modeling framework to analyze interdependencies among infrastructure systems', Transp. Res. Part B Methodol., Vol. 45, No. 3, pp.553-579. 
Zimmerman, R. (2001) 'Social implications of infrastructure network interactions', J. Urban Technol., Vol. 8, No. 3, pp.97-119.

Zimmerman, R. (2006) 'Critical infrastructure and interdependency', in Kamien, D.G. (Ed.): The McGraw-Hill Homeland Security Handbook, McGraw-Hill Professional, New York, USA.

Zimmerman, R. (2008) 'Understanding the implications of critical infrastructure interdependencies for water', in Voeller, J.G. (Ed.): Wiley Handbook of Science and Technology for Homeland Security, John Wiley \& Sons, Inc., Hoboken, NJ, USA.

Zimmerman, R. and Restrepo, C.E. (2006) 'The next step: quantifying infrastructure interdependencies to improve security', Int. J. Crit. Infrastructures, Vol. 2, Nos. 2/3, pp.215-230. 